\title{
OS “MÚLTIPLOS” DIREITOS E OBRIGAÇÕES DO CIDADÃO DO MERCOSUL. SIGNIFICADOS E ALCANCE DA CIDADANIA
}

LOS “MÚLTIPLES” DERECHOS Y OBLIGACIONES DEL CIUDADANO EN EL MERCOSUR. SIGNIFICADOS Y ALCANCE DE LA CIUDADANÍA

Alejandra Díaz

Resumo: O significado e o alcance do conceito de cidadania em espaços integrados constitui o objeto de análise do trabalho. Em particular, seu desenvolvimento no MERCOSUL. Adicionalmente, observa-se o impacto do conceito na tomada de decisões e no desenho dos órgãos do MERCOSUL e os direitos e obrigações que envolvem a cidadania à luz da evolução que essa, em tempos recentes, teve na esfera da integração regional. A criação do Parlamento do MERCOSUL, por exemplo, pode ser proposta como fase na construção e no exercício dos direitos e deveres dos destinatários genuínos do processo de integração regional.

Resumen: El objeto de análisis es el significado y alcance del concepto de ciudadanía en espacios integrados. En particular, el desarrollo en el ámbito MERCOSUR. Adicionalmente, se observará el impacto del término en la toma de decisiones y en el diseño de los órganos mercosureños. La ciudadanía y los derechos y obligaciones que conlleva a la luz de la evolución que, en tiempos recientes, ha tenido en el ámbito de la integración regional. La creación del Parlamento MERCOSUR puede proponerse como una fase en la construcción y ejercicio de los derechos y deberes de los destinatarios genuinos del proceso de integración regional.

Palavras-chave: Cidadania, Direitos, Obrigações, Parlamento, Participação, Partidos políticos, Regulamentação jurídica, União Europeia, Mercosul

Palabras clave: Ciudadanía, Derechos, Obligaciones, Parlamento, Participación, Partidos políticos, Regulación jurídica, Unión Europea, Mercosur

* Tradução: Prof. Raphael Carvalho de Vasconcelos.

** Licenciada em Ciência Política pela Faculdade de Ciências Sociais da Universidade de Buenos Aires. Mestranda no Mestrado de Desenvolvimento da Norma Jurídica da Faculdade de Direito da Universidade de Buenos Aires. Professor da Faculdade de Direito da Universidade de Buenos Aires, da Universidade Nacional de La Matanza eo Ciclo Básico Comum. 


\section{INTRODUÇÃO}

O Mercado Comum do Sul - MERCOSUL - se transformou em uma região que conquistou avanços na integração em várias áreas em consonância com os objetivos previstos no Tratado de Assunção e nos protocolos celebrados posteriormente.

Até o momento, as decisões institucionais foram tomadas em dinâmica intergovernamental no MERCOSUL. Por essa razão, as decisões se concentraram nos órgãos executivos nacionais sem um marco institucional que ampliasse a representação ou que tenha criado pontes que facilitassem a participação da sociedade civil.

De fato, como observa Sandra Negro, os valores democráticos que conduzem à participação da cidadania na tomada de decisões

"no aparece como una preocupación en las primeras etapas de los procesos de integración, en los cuales la iniciativa reconoce impulsos gubernamentales $y$, en particular, de las áreas técnicas de gobierno con escasa o nula participación de los ciudadanos en las instituciones $\mathrm{u}$ órganos creados. Las experiencias europeas y americanas ponen en evidencia que, en el nacimiento y en las primeras etapas de los esquemas de integración, no hubo participación directa, en la deliberación ni en la elección de representantes y, menos aún, en la toma de decisiones por parte de los ciudadanos. Es decir que, conforme evolucionan, empieza a manifestarse cierta disociación y a percibirse el desconocimiento del conjunto respecto de los beneficios y las ventajas que los esquemas de integración económica pueden ofrecer a los ciudadanos. En realidad, en el origen, el impulso inicial corresponde a los gobiernos y sólo conforme la integración evoluciona, se da participación directa a asociaciones intermedias y a la ciudadanía en su conjunto. Una de las principales críticas que se han formulado respecto de los procesos de integración en curso reside en el hecho de que son demasiadas las decisiones capaces de afectar la vida de los ciudadanos que se toman sin la debida transparencia, publicidad y participación"'.

Disso resultou um aparente "déficit democrático" no processo de integração sub-regional.

"La emergencia del Mercosur amplia las fronteras, diseña un nuevo mapa, redefine los escenarios para la acción colectiva y modela un

1 NEGRO Sandra (2013) "Caracterización y clasificación de los esquemas de integración", en NEGRO Sandra (dir.) Derecho a la Integración Regional. Manual. 2da. ed. Buenos Aires: Euroeditores/Ed BdeF; p 45-46. Agrega Sandra Negro que "en el caso europeo, el denominado 'déficit democrático' y la proximidad del ciudadano a los centros de toma de decisiones han sido motivo de sucesivas disposiciones tendientes a mejorar el sistema que ya lleva más de cincuenta años de vida". 
nuevo "demos", todo lo cual requiere de decisiones imaginativas capaces de dar cuenta de la emergencia de la "región" con un actor que se agrega a los Estados nacionales" 2 .

Faz-se necessário cultivar ferramentas e criar instituições que possam levar à superação do "déficit democrático" para alcançar a participação e o compromisso da sociedade civil na evolução do processo de integração. Torna-se necessário pensar esferas, nas quais esse "demos" possa participar representativamente na estrutura da integração. Para sanar a questão, firmou-se em 09 de dezembro de 2005 o Protocolo Constitutivo do Parlamento do MERCOSUL, o qual deveria ser integrado por meio de voto direto, universal e secreto a partir de 2011 e que em 2015 já deveria contar com eleições simultâneas dos parlamentares mercosulinos. Contudo, até abril de 2013 o único país que elegeu por voto direto, secreto e universal os legisladores do Parlasul foi o Paraguai. Como se vê, os prazos não foram cumpridos.

Considera-se necessária a instituição de direitos positivos aos integrantes da sociedade tanto em termos individuais quanto coletivos. O MERCOSUL também considerou o mesmo e estabeleceu na decisão 64/10 do Conselho Mercado Comum - CMC, na qual se estrutura um plano de ação para conformar um Estatuto da Cidadania do MERCOSUL de forma progressiva que deve estar pronto para implementação em 2021.

É de se considerar, entretanto, que os prazos deveriam ser encurtados para que se fizesse possível a possibilidade de um melhor e mais substancial gozo de direitos pelos habitantes do espaço ampliado. Mas, além disso, observa-se que para fortalecer o funcionamento da estrutura orgânica da organização faz-se necessário controlar as ações levadas a cabo pelos órgãos do processo de integração.

O Parlamento do Mercado Comum do Sul foi criado, conforme mencionado, com a finalidade de se concretizar uma adequada e plena representação política dos povos dos Estados Parte. Considerando que não pode haver construção política democrática sem a participação direta da população e que é dever dos Estados Nacionais reconhecer e garantir direitos e liberdades a seus habitantes, evidente se faz a necessidade de se reconhecerem em curto prazo, por meio de um protocolo, direitos (extensivos a toda a população de cada membro do esquema). Faz-se referência, nesse sentido, a já clássica tríade de direitos: civis, políticos e sociais que desenvolveu Thomas H. Marshall ${ }^{3}$.

2 EMILIOZZI Sergio (2007) "La democracia en la integración: política, instituciones y ciudadanía en el Mercosur". In EMILIOZZI, PECHENY, UNZUÉ (coords.) La dinámica de la democracia. Representación, instituciones y ciudadanía en Argentina. Buenos Ares: Prometeo Libros, p. 252.

3 MARSHALL T.H. e BOTTOMORE Tom (1998) Ciudadanía y clase social. Madrid: Ed. Alianza. 


\section{A QUE SE REFERE A CIDADANIA?}

Quando se trata de cidadania, faz-se referência à titularidade plena de direitos públicos subjetivos civis, políticos, e sociais - e nos últimos 20 anos - de econômicos e culturais reconhecidos e outorgados pelo sistema jurídico. À luz de Thomas H. Marshall pode-se afirmar que, ao se fazer referência a direitos civis, há que se pensar no elemento civil e a partir dele fazer-se referência a um conjunto de direitos indispensáveis à liberdade individual, à liberdade pessoal, à liberdade de expressão, à liberdade de pensamento, à liberdade de consciência, à liberdade de ir e vir e à liberdade de informação, também o direito à propriedade e o direito de celebrar contratos válidos e logicamente o direito à justiça.

Por outro lado, ao se focalizar o elemento político, disponível se encontra outra gama de direitos necessários à participação no exercício do poder político, o direito a poder ser um membro de um corpo social investido de autoridade política, direito de eleger os membros que compõem o corpo da autoridade política, ter o direito de peticionar às autoridades. Por último, quando se fala de elemento social, faz-se referência ao alcance amplo que o termo abarca desde o direito do trabalho, o direito de aprender e ensinar, o direito de alcançar um mínimo de bem-estar econômico e de segurança.

Os direitos de terceira e de quarta geração, como podem ser considerados os direitos econômicos, culturais, e ambientais não são levados em conta no desenvolvimento desse trabalho, posto se sustentar a necessidade de se instituírem direitos cidadãos e, como se sabe, a liberdade vicia e quando se alcança o reconhecimento e a garantia das questões básicas que foram enumeradas, a abertura das liberdades leva diretamente à integração dos direitos difusos.

A cidadania também tem um componente de nacionalidade, já que em uma concepção ampla pode ser definida como a "condição jurídica de quem forma parte de um Estado"4. Em geral, vários pontos ao redor da cidadania estão estreitamente relacionados com a nacionalidade, a saber: os critérios para outorgá-la seja por meio do padrão ius sanguinis ou do ius solis; o direito do Estado de outorgar ou de negar, em seus limites, a nacionalidade a certos indivíduos ou pessoas jurídicas; a possibilidade de o indivíduo renunciar a nacionalidade; a proteção jurídica dada pelo Estado aos seus nacionais onde quer que se encontrem; o tratamento que se dá a estrangeiros em termos jurídicos. A nacionalidade constitui um pressuposto indispensável para o direito à cidadania. Digamos que esta supõe pressupostos mínimos. A saber; tem como requisitos mínimos a nacionalidade e a maioridade (limite legal de idade para poder começar a exercer plenamente o direito).

4 GUTIÉRREZ Carlos José. Ciudadanía. [online] disponível em: <http://www.iidh.ed.cr/ comunidades/redelectoral/docs/red_diccionario/ciudadania.htm $>$ [acesso em mayo de 2013]. 
Quem sabe seja possível encontrar uma explicação substancial no que diz Jean Rivero ${ }^{5}$ sobre o conceito de cidadão que surge da Declaração dos Direitos do Homem e do Cidadão de 27 de agosto de 1789, aprovada pela Assembléia Nacional Francesa revolucionária:

"La dualidad que aparece en el titulo de la Declaración debe ser explicada. Los derechos del hombre son (...) anteriores a la sociedad. Pero, los derechos del ciudadano no se conciben sino cuando la sociedad ha sido creada. Hay entonces entre ellos, una diferencia de naturaleza (...) Los derechos de los ciudadanos son los corolarios necesarios a los derechos del hombre (...)

Los derechos del hombre son libertades. Le permiten al hombre conducir una vida personal, como él la entienda. Le confieren una era de autonomía dentro de la cual la sociedad no puede inmiscuirse (...) Los derechos del ciudadano son poderes; aseguran la participación de todos en la conducción de la ciudad. Por eso, excluyen toda posibilidad de opresión por parte de ella: ellos son el derecho de concurrir a la formación de la voluntad general (art.6), el derecho de consentir en los impuestos (art.19), etc. (...)

Esta distinción corresponde, en realidad a dos concepciones diferentes de la libertad, que Benjamín Constant ha sistematizado en la oposición entre libertad política, o libertad de los antiguos y libertad civil o libertad de los modernos. Dentro de la ciudad griega, la participación en la decisión política en el seno de la asamblea del pueblo era la única expresión de la libertad (...) Los "modernos" aspiraban menos a participar en el poder que a sustraer de su ámbito la conducción de sus existencia: la libertad "civil" (en el sentido que uno habla de "derecho civil" en oposición al derecho "público") es la verdadera libertad (...) Dentro de la Declaración, las dos categorías, lejos de oponerse, son indisolubles".

Esses conceitos mostram a maneira pela qual o pensamento jurídico francês entende a cidadania: como expressão dos direitos políticos.

Em definitivo, a cidadania dá direitos civis, políticos, sociais e difusos, mas também impõe deveres e obrigações.

\section{COMO PENSARACIDADANIAEMTERMOS DEINTEGRAÇÃO}

Para que se possa apresentar a idéia de cidadania em um processo de integração, mostra-se útil recorrer ao esquema que está mais

5 Ibíd., GUTIÉRREZ cita a RIVERO Jean (1974) Les Libertés Publiques. Les Droits de l'homme. Paris: Presses Universitaires de France, p. 45

6 GUTIÉRREZ, Op. cit. 
consolidado: a União Européia - UE. A UE introduz o tema no Tratado de Maastricht em 1992, ali a cidadania regional se define como "uma qualidade de cidadão do Estado membro". Seguindo os aportes de Chiaretto, ressalta-se:

"El art.17 del TCE con la modificación introducida por el Tratado de Maastricht recita:" Será ciudadano de la Unión toda persona que ostente la nacionalidad de un Estado miembro: la Ciudadanía de Unión será complementaria y no sustitutiva en la ciudadanía nacional".

De aquí la consecuencia que (...) los ciudadanos de la Unión serán titulares de los derechos (y sujetos de los deberes) previstos directamente en el Tratado"7.

A partir desse ponto de vista, o cidadão do processo de integração deve ser pensado como um cidadão múltiplo que atua e participa em diversos cenários políticos, os quais não são excludentes, mas - na verdade - complementares. E aqui a questão-chave seria "participar". Para que se faça possível a participação do cidadão não seria suficiente fixar os direitos de cidadania e seria necessário também dar ferramentas para que essa cidadania encontre canais certos de participação. Sobre tal questão vale recorrer novamente ao caso da UE que, mesmo tendo há anos um Parlamento que funciona com composição eleita por meio de sufrágio universal pelo povo de cada Estado membro, não conseguiu superar a supremacia da tomada de decisões em um modelo intergovernamental que teve como resultado o reforço "del papel de los Ejecutivos Nacionales a costa del poder de influencia y de control de los parlamentos y de los partidos políticos"8.

Oportuno se faz destacar que o desenho institucional do MERCOSUL constituiu órgãos com capacidade decisória e órgãos consultivos. Os primeiros são o Conselho Mercado Comum (CMC), o Grupo Mercado Comum (GMC) e a Comissão de Comércio do MERCOSUL (CCM); por outro lado, os órgãos consultivos são a Comissão Parlamentar Conjunta que algum tempo depois se transformou no ParlaSur (instituído pelo Protocolo de criação do Parlamento do MERCOSUL) e o Foro Consultivo Econômico e Social. Os órgãos com capacidade decisória abarcam os Ministros de Relações Exteriores e os Ministros da Economia e até mesmo os Chefes e Chefas dos Estados que se reúnem ao menos duas vezes ao ano. Por outro lado, também foram criadas comissões, comitês, grupos e subgrupos

7 CHAIRETTO Elisa (2008) "La libre circulación de las personas como factor de integración en la Unión Europea". In LEITA Francisco e NEGRO Sandra (coords.) La Unión Europea y el Mercosur: a 50 años de la firma de los Tratados de Roma. Buenos Aires: La Ley, p. 88.

8 "2014 ¿Las primeras elecciones "europeas"?”. Más Europa. Historia, actualidad y futuro de la integración europea. [online] disponível em: <http://encarnahernandez.wordpress. com/2013/03/15/2014-las-primeras-elecciones-europeas/> [acesso em mayo de 2013]. 
com incumbências específicas que não parecem ter melhor destino que o descrito. Isso explicaria o que se sustenta acerca da supremacia intergovernamental nas decisões e na condução desse processo político de integração.

\section{A CIDADANIA NO MERCOSUL}

A forma de se superar o "déficit democrático" de que sofre o processo de integração do MERCOSUL seria incrementando a participação da sociedade civil. Para tanto, necessário se faria dotá-la de direitos e seus integrantes da condição cidadã. Necessário se faria que os cidadãos dos Estados Partes adquirissem a condição de cidadãos do MERCOSUL, adicionando-a à sua cidadania nacional. Para tanto, deve-se ter em conta alguns temas que seriam essenciais para a cidadania, a saber: o princípio da igualdade, a titularidade de direitos, a representação parlamentar, a participação política, o direito de peticionar, a proteção consular, a não discriminação, o acesso á informação e a livre circulação de pessoas. Esses pontos, selecionados arbitrariamente a partir de uma quantidade muito ampla de direitos civis, políticos e sociais, são, entende-se, o mínimo que se pode exigir como indispensável ao se falar de cidadania.

É fundamental pensar o cidadão do MERCOSUL a partir de um princípio de igualdade, o qual implica respeito a todos os indivíduos no que se refere ao normal tratamento de todas as suas atividades. Por esse motivo, os órgãos e organismos do MERCOSUL deveriam prestar atenção de forma isonômica às diversas pretensões manifestadas pela cidadania. Os cidadãos dos Estados devem ser beneficiados igualitariamente do acesso às instituições e às esferas de participação abertas aos cidadãos do MERCOSUL, por exemplo, das eleições parlamentares.

Não seria menos importante sustentar e manifestar claramente que aqueles que foram cidadãos da organização seriam titulares de direitos e estariam sujeitos a deveres estabelecidos no marco jurídico criado a partir do Tratado de Assunção e dos instrumentos posteriormente assinados e, em particular, pelas normas de caráter vinculante emanadas por seus órgãos. Entende-se, nesse sentido, que não haveria dúvidas quanto à titularidade de direitos decorrentes de seu pertencimento ao MERCOSUL. Isso se faz importante para evitar qualquer vício de desigualdade no gozo de direitos entre os cidadãos, ou seja, que um cidadão de um Estado pequeno e outro de um Estado grande estejam equiparados em igualdade de direitos mais além das assimetrias reais que possam se dar em termos políticos e econômicos entre os Estados. Como se percebe, a titularidade de direitos exige o princípio da igualdade para que o direito de cidadania seja real. 


\section{O RECONHECIMENTO DO ELEMENTO POLÍTICO DA CIDADANIA}

Parece evidente que a instituição mais ligada à participação popular seja o Parlamento do MERCOSUL, cuja criação já se mencionou anteriormente, surge com a pretensão de constituir um órgão de representação da pluralidade política e ideológica dos povos dos Estados Parte do MERCOSUL. Entre seus propósitos se encontrariam a assunção da promoção e da defesa permanente da democracia, o impulso do desenvolvimento sustentável da região, a guarda do respeito à diversidade cultural das populações, etc. Seu funcionamento pleno se encontra com anos de atraso, posto não terem sido cumpridos os prazos estabelecidos no Protocolo fundacional - que obrigou sua extensão em várias ocasiões.

A existência de instituição com tais características exige que se assegure aos cidadãos do MERCOSUL o direito ao sufrágio ativo e passivo nas eleições do referido Parlamento e à participação plena no processo de integração. Isso poderia ser alcançado se fosse criado um sistema de consulta popular por meio de referendo que fosse vinculante para as questões mais transcendentes dentro do processo de integração ou inclusive por meio do instituto da iniciativa popular que poderia ser levado adiante por parte de um numeroso grupo de cidadãos nacionais de vários Estados Parte, os quais teriam a possibilidade de exigir a apresentação de uma proposta adequada sobre temas que considerassem de necessária solução jurídica por parte das instituições do MERCOSUL 9 .

\footnotetext{
9 Explica Carlos Francisco Molina del Pozo, em “La participación ciudadana a través de la iniciativa popular”. In MOLINA DEL POZO Carlos F. e PIZZOLO Calógero (2011) (coords.) El Parlamento de la Unión Europea y el Parlamento del Mercosur. Ensayos sobre un estudio comparado. Buenos Aires: Eudeba, p. 223-224, como funciona na UE, e fala: "Ahora, sin embargo, el Tratado de Lisboa, en el art. $11 \mathrm{~N}^{\circ} 4$ del TUE, y tras su inclusión en el non nato Tratado Constitucional, viene a recoger una clara ampliación del derecho de iniciativa legislativa a favor de los ciudadanos, a través de los que se denomina la iniciativa ciudadana o iniciativa popular.

En efecto, el mencionado precepto del TUE, como antes lo hiciera el art. 47 de la Parte I del Tratado Constitucional, cuyo enunciado copia literalmente el Tratado de Lisboa, establece que un grupo de al menos un millón de ciudadanos de la Unión que sean nacionales de un número significativos de Estados miembros podrán adoptar la iniciativa de invitar a la Comisión Europea, en el contexto de sus atribuciones, a que presente una propuesta adecuada sobre cuestiones que esos ciudadanos estimen que requieren un acto jurídico de la Unión para los fines de la aplicación del los Tratados.

Así el texto del vigente Tratado de la Unión Europea También permite, desde su entrada en vigor, el 1 de diciembre de 2009, que un número superior al millón de personas, pertenecientes a un grupo significativo de Estados miembro, puedan tomar la iniciativa de sugerir a la Comisión para que, en el marco de las atribuciones que tiene conferida, presente una propuesta adecuada acerca de ámbitos temáticos sobre los que los reiterados grupos de ciudadanos consideren que es precisa su regulación a través de un acto jurídico de la Unión, con objeto de lograr los fines de la aplicación de los Tratados. De manera que se trata, una vez más, de un derecho de iniciativa legislativa que, asimismo, podríamos calificar como de carácter indirecto”.
} 
Noutro sentido, deve-se considerar a migração interna e abrir espaços de participação e inserção políticas daqueles que se estabeleceram em uma localidade que não se encontra em seu país de origem. Assim, poder-se-ia estabelecer, por exemplo, que os cidadãos do MERCOSUL possuem direitos de participar das eleições municipais dos Estados Parte em que residam nas mesmas condições dos nacionais do referido Estado. Desde já para que isso possa ser implementado em termos operativos, cada Estado Parte teria que regulamentar o exercício do referido direito em sua legislação nacional. Tal medida permitiria que muita gente assentada desde muito tempo em um país estrangeiro, ainda que membro da organização, pudesse participar de assuntos que o atingissem diretamente no município, permitindo, assim, que possa se comprometer e integrar de forma propositiva. Além disso, poderia ser gerada uma ampliação da política por meio de uma relação mais cooperativa que poderia gerar laços solidários dentro da comunidade municipal.

Outro tema que pertence à esfera política seria o direito de peticionar. Um dos temas mais discutidos entre os Founding Fathers norte-americanos quando criaram seu sistema, baseado na democracia liberal foi o de se o povo (cidadãos) deveria intervir na tomada de decisão. Chegaram à conclusão de que o povo não delibera e nem governa, já que para isso elege representantes. Contudo, levando-se em consideração que os representantes possuem autonomia e independência para tomar decisões que sejam apresentadas no exercício da representação, permite-se ao povo que peticione às autoridades. A partir desse ponto de vista, torna-se necessário incluir entre os direitos dos cidadãos do MERCOSUL o direito de peticionar perante a Comissão de Comércio, o Grupo Mercado Comum e o Parlamento do MERCOSUL; bem como de recorrer a qualquer órgão que seja criado posteriormente para defender os direitos relativos ao exercício da cidadania no MERCOSUL. Também deve ser reconhecido o direito de se dirigir a qualquer dos órgãos consultivos na qualidade de peticionante. Logicamente, tudo isso apenas faria sentido se as instituições fossem obrigadas a responder os requerimentos dos cidadãos em um prazo relativamente aceitável.

Não se pode perder de vista que não está previsto, até o momento, no interior dos órgãos do MERCOSUL que uma pessoa física cidadã de um Estado Parte possa provocar alguma instância em seus organismos.

Seria necessária, então, a criação de um organismo ou instituição que tenha como tarefa a recepção de demandas apresentadas pelos cidadãos relacionada ao respeito de seus direitos e à garantia de algum tipo de "poder de polícia" para assegurar o exercício efetivo dos direitos do cidadão do MERCOSUL. 


\section{A PROTEÇÃO DO MERCOSUL A TODOS OS SEUS CIDADÃOS}

Se os habitantes dos Estados Parte fossem cidadãos do MERCOSUL, pode-se imaginar que possuiriam direito de receber, no território de um terceiro país em que não esteja representado o Estado Parte do qual seja nacional, a proteção das autoridades diplomáticas e consulares de qualquer outro Estado Parte, nas mesmas condições dos nacionais do referido Estado. Em sendo cidadão regional, deveria poder recorrer à proteção de qualquer de seus membros perante terceiros Estados.

Desde já que esse tema requeriria uma adequação das legislações nacionais para reconhecer direitos a cidadãos do MERCOSUL que não forem nacionais e os que estariam obrigados a protegê-los.

Pode-se relacionar com o tema descrito o princípio da não discriminação exatamente no que se refere a terceiros Estados. Mas quando se faz referência simplesmente à não discriminação, possível se faz vislumbrá-la de maneira projetiva no interior do MERCOSUL. Assim sendo, deveria ser estabelecido no marco da aplicação do Tratado de Assunção e dos protocolos adotados posteriormente - e sem prejuízo às disposições particulares previstas nos mesmos - que se proíbe toda discriminação por razão de nacionalidade, etnia, religião, condição sexual, gênero e/ou capacidades diferentes. Isso seria, em princípio, um importante estimulo para dirimir conflitos baseados nessas diferenciações que são levadas ao extremo por preconceito, muitas vezes, cultural.

Considera-se, assim, que o Parlamento do MERCOSUL poderia cumprir um papel preponderante por meio de procedimento legislativo ordinário, formulando as recomendações necessárias com a finalidade de velar pelo efetivo cumprimento desse princípio. Nesse mesmo sentido, seria possível investir o Grupo Mercado Comum e a Comissão de Comércio da atribuição de adotar disposições vinculantes necessárias ao cumprimento da finalidade de se implementar efetivamente procedimentos contra a discriminação.

\section{O ELEMENTO CIVIL DENTRO DA CIDADANIA}

Os cidadãos do MERCOSUL têm direito a ter acesso a toda informação gerada pelos órgãos do MERCOSUL, e - em particular - à sua normativa derivada de caráter vinculante no marco do processo de integração. Poderão solicitar acesso a toda documentação que se encontre na posse dos órgãos do MERCOSUL que se revista de caráter público, em qualquer formato, obtendo resposta em no máximo 20 dias, e solicitando que não se divulguem sem seu conhecimento documentos que se refiram diretamente à pessoa e que sejam considerados confidenciais por direito. 
Outro tema que parece um pouco mais debatido seria o da livre circulação de pessoas. Faz-se evidente que se deverá regular cuidadosamente o tema já que, levando-se em conta as assimetrias entre os Estados Parte no que se refere a suas economias e aos direitos sociais que cada um reconheça, poderia produzir um forte desequilíbrio migratório, afetando fortemente as condições internas das unidades nacionais. Mas sobre esse ponto também se pode analisar a experiência da União Européia, a qual estabelece por meio de instituições determinadas regulamentações limitativas para alcançar a atenuação da livre circulação de pessoas,

"donde reafirma que todo ciudadano de la Unión tiene derecho de residencia en el territorio de otro Estado miembro por un periodo superior a 3 meses si es un trabajador por cuenta ajena o por cuenta propia en el Estado miembro de acogida, o dispone para sí y los miembros de su familia, de recursos suficientes para no convertirse en una carga para la asistencia social del Estado miembro de acogida durante su período de residencia, así como de un seguro de enfermedad que cubra todos los riesgos en el Estado miembro de acogida (art. 7)"10.

Não se pode assegurar que esta seria a solução mais acertada. Deve-se, entretanto, admitir a necessidade de se reconhecer a livre circulação de pessoas e que a atenuação desse direito ao menos até que se possam harmonizar as economias dos Estados Partes poderia constituir a melhor saída ao dilema.

\section{EL ELEMENTO SOCIAL DEL COMPONENTE DE LOS DERECHOS}

Segundo Emiliozzi ${ }^{11}$, uma das formas de se solucionar o déficit democrático seria a construção de uma cidadania social a partir da própria sociedade. Nesse sentido, para que se buscassem caminhos de integração social em tentativa de se mitigar a pobreza e construir a cidadania, criou-se o Foro Consultivo Econômico e Social (FCES). Mario A.R. Midón ressalta:

"Aunque nacido formalmente en Ouro Preto, el Foro Consultivo Económico-Social recién cobro vida a fines de mayo de 1996, cuando las partes suscribieron el acto No 1 por la cual se declaró su constitución, y dicto su reglamento, luego aprobado por la Resolución 68/96 del GMC.

10 CHAIRETTO Op. cit. p. 90.

11 Tambén é possível consultar o tema em EMILIOZZI Sergio (2006) "La construcción de la ciudadanía en el MERCOSUR". KAIRÓS, Revista de Temas Sociales Proyecto "Culturas Juveniles Urbanas" Universidad Nacional de San Luis, 10(17), p. 1-10. [online] disponível em: $<$ http:www.revistakairos.org > [acesso em mayo de 2013]. 
Por lo pronto, la aparición de un órgano como el que nos ocupa sugiere la preocupación del legislador para paliar el déficit democrático que el proceso de integración mercosuriano acusa desde sus orígenes.

En esa idea, la competencia asignada al cuerpo parece responder al mismo propósito que en su momento animó la idea del Comité Económico y Social de la Comunidad Europea, el que desarrolló una destacada labor en la elaboración de la política social de aquel modelo, con la participación de empresarios, trabajadores y diversos grupos"12.

O FCES se encontra integrado por representantes de empresários (capital)e de sindicatos (trabalhadores), por associações de consumidores etc. Importante se faz ressaltar que um dos escassos campos explorados na estrutura institucional desse esquema regional que dá espaço à sociedade civil para participar e interferir no processo de construção da integração fazendo suas demandas visíveis e interagindo com diversos atores de distintos Estados Parte. No seio do Foro foram constituídos diversos grupos de trabalho e ao mesmo tempo os funcionários do Foro podem participar das sessões do CMC.

Nessa esfera estão sendo tratados temas como: a circulação de mão de obra e a promoção dos direitos dos trabalhadores dentro da organização. Tomou-se um problema a ser resolvido o tema dos imigrantes em relação ao qual se negocia a residência para os nacionais do MERCOSUL e também sua regularização migratória. Também se busca o reconhecimento mútuo de títulos profissionais dos Estados Parte que permita a livre circulação de profissionais e o desenvolvimento normal de suas atividades laborais.

"Junto al tratamiento de las asimetrías estructurales desde una perspectiva subregional, la integración productiva y el apoyo a las PYMES, la dimensión social del proceso de integración se ha convertido también en los últimos años en motivo de renovado interés para los Estados Partes, y cuya muestra más concreta, aunque no en los plazos originalmente previstos, la constituye la creación en 2001 del Instituto Social del MERCOSUR entre sus funciones se cuentan, las de:

1-Proporcionar colaboración técnica en el diseño y planificación de proyectos sociales.

2-Promover la investigación con el fin de apoyar la toma de decisión en el diseño y puesta en marcha de políticas y programas sociales.

3 -Sisteatizar y difundir las mejores experiencias y prácticas en materia social del MERCOSUR, continente y extracontinentales.

4- Recopilar información sobre la marcha de la situación social en la

12 MIDÓN Mario A.R. (1998) Derecho de la Integración. Buenos Aires: Rubinzal-Culzoni Editores, p. 318-319. 
región"13.

Outro órgão que cumpre função semelhante seria o Fundo para a Convergência Estrutural do MERCOSUL (FOCEM),

"La finalidad del FOCEM es financiar programas destinados a:

-promover la convergencia estructural,

-desarrollar la competitividad,

-fomentar la cohesión social, en especial de las economías menores y regiones menos desarrolladas,

-apoyar el funcionamiento de la estructura institucional, $y$

-fortalecer el proceso de integración"14.

Essas estruturas que foram mencionadas podem ser consideradas inspiradas em instituições análogas da União Européia e da Comunidade Européia ${ }^{15}$.

\section{REFLEXÕES FINAIS}

O momento atual do processo de integração do MERCOSUL apresenta a necessidade de se construir uma cidadania capaz de dotar a sociedade civil de ferramentas jurídicas hábeis a promover sua participação na criação da estrutura de relações jurídico-políticas que no MERCOSUL sempre estiveram nas mãos dos executivos nacionais. Útil se faz reconhecer que o MERCOSUL não nasceu com um DNA democrático, mas muito mais como uma construção intergovernamental que daria posteriormente passos lentos e dependentes dos governos. Apesar de alguns terem sonhado com uma construção de caráter supranacional, não foi isso que surgiu dos acordos e instrumentos fundacionais. $\mathrm{O}$ compromisso com a integração no MERCOSUL exige que se envolva a população no processo para que o sintam como seu e que não o vejam como algo alheio.

Fundamental se faz que a participação se proceda de maneira correta, ou seja, que o Parlamento do MERCOSUL seja finalmente constituído por sufrágio universal, direto e secreto já que talvez assim os grandes temas do MERCOSUL se tornarão cotidianos e a população

13 MOCCERO María M. (2012) "El escenario actual del MERCOSUR". In NEGRO Sandra (coord.) Lecturas sobre Integración Regional y Comercio Internacional. Buenos Aires: La Ley, p. 423-424.

14 CZAR DE ZALDUENDO Susana (2007) "La creación del FOCEM: importante decisión en el MERCOSUR”. In BARRAL Welber y CORREA Carlos (orgs.) Derecho, desarrollo y sistema multilateral del comercio. Florianópolis : Fundación Boiteux, p. 209.

15 Para mais informações sobre este tema, ver em NEGRO Sandra (2007) "Integración y desequilibrios regionales en la Unión Europea: cohesión económica y social y fondos estructurales". In BARRAL Welber y CORREA Carlos (orgs.) Derecho, desarrollo y sistema multilateral del comercio. Florianópolis: Fundación Boiteux, p. 221-244. 
dos países que o integram poderão ter consciência de tudo o que implica essa organização internacional sub-regional.

Também conformaria experiência enriquecedora se aquilo que se discute no Foro Consultivo Econômico e Social não estivesse reservado para apenas algumas pessoas e que o debate pudesse transcender suas paredes e que os temas fossem, portanto, amplamente discutidos.

Seria momento de se agregar à conquista da cidadania nacional uma nova cidadania: diferente e que amplie espaços e direitos. Uma boa construção jurídica institucionalizaria condutas e ampliaria as esferas de participação para os cidadãos. $\mathrm{O}$ que, muito provavelmente, tornaria mais compreensível a importância do desenvolvimento do MERCOSUL para o cidadão comum. Quem sabe, caso se consiga isso, caberia o questionamento do desejo de que o MERCOSUL siga sendo uma construção regional com tendências de integração ou se deveria caminhar em direção a uma construção supranacional.

Por último, de se considerar seria que não há construção democrática sem cidadania e que esta não se faz possível sem o reconhecimento e a garantia de direitos e deveres. Não teria sentido, portanto, tratar de "déficit democrático" se não se pretendesse incluir a cidadania na construção de uma estrutura supranacional.

\section{REFERÊNCIAS BIBLIOGRÁFICAS}

“2014 ¿Las primeras elecciones "europeas"?”. Más Europa. Historia, actualidad y futuro de la integración europea. [online] disponível em: <http://encarnahernandez.wordpress.com/2013/03/15/2014-lasprimeras-elecciones-europeas/> [acesso em mayo de 2013].

CZAR DE ZALDUENDO Susana (2007) "La creación del FOCEM: importante decisión en el MERCOSUR": In BARRAL Welber e CORREA Carlos (orgs.) Derecho, desarrollo y sistema multilateral del comercio. Florianópolis : Fundación Boiteux , p. 209.

CHAIRETTO Elisa (2008) "La libre circulación de las personas como factor de integración en la Unión Europea”. In LEITA Francisco e NEGRO Sandra (coords.) La Unión Europea y el Mercosur: a 50 años de la firma de los Tratados de Roma. Buenos Aires: La Ley, p. 88.

EMILIOZZI Sergio (2006) "La construcción de la ciudadanía en el MERCOSUR". KAIRÓS, Revista de Temas Sociales Proyecto "Culturas Juveniles Urbanas" Universidad Nacional de San Luis, 10(17), p. 1-10. [online] disponível em: <http:www.revistakairos.org > [acesso em mayo de 2013].

EMILIOZZI Sergio (2007) "La democracia en la integración: política, instituciones y ciudadanía en el Mercosur". In EMILIOZZI, PECHENY, UNZUÉ (coords.) La dinámica de la democracia. Representación, instituciones y ciudadanía en Argentina. Buenos Ares: Prometeo Libros, p. 252. 
MARSHALL T.H. y BOTTOMORE Tom (1998) Ciudadanía y clase social. Madrid: Ed. Alianza.

MERCOSUR (1994) Protocolo de Ouro Preto. [online] disponível em: $<$ http://www.mercosur.int/innovaportal/file/99/1/span_class=liushitouro_ span_span_class=liushitpreto_span_es.pdf $>$ [acesso em mayo de 2013].

MERCOSUR (2005) Protocolo constitutivo del Parlamento del MERCOSUR. [online] disponível em: < http:/www.mercosur.int/innovaportal/ file/1104/1/2005_protocoloparlamentomcs_es.pdf> [acesso em mayo de 2013].

MERCOSUR (2010) Estatuto de Ciudadanía del MERCOSUR. Plan de acción. [online] disponível em: <http://www.mercosur.int/innovaportal/ file/2808/1/DEC_064-2010_ES_Estatuto\%20de\%20Cidadania.pdf> [acesso em mayo de 2013].

MIDÓN Mario A.R. (1998) Derecho de la Integración. Buenos Aires: Rubinzal-Culzoni Editores, p. 318-319.

MOCCERO María M. (2012) "El escenario actual del MERCOSUR”, en NEGRO Sandra (coord.) Lecturas sobre Integración Regional y Comercio Internacional. Buenos Aires: La Ley, p. 423-424.

MOLINA DEL POZO Carlos F. (2011) "La participación ciudadana a través de la iniciativa popular". In MOLINA DEL POZO Carlos F. e PIZZOLO Calógero (coords.) El Parlamento de la Unión Europea y el Parlamento del Mercosur. Ensayos sobre un estudio comparado. Buenos Aires: Eudeba, p. 223-224.

NAL PENGUIN (edit.) (1961) The Federalist Papers.

NEGRO Sandra (2007) "Integración y desequilibrios regionales en la Unión Europea: cohesión económica y social y fondos estructurales”. In BARRAL Welber e CORREA Carlos (orgs.) Derecho, desarrollo y sistema multilateral del comercio. Florianópolis: Fundación Boiteux, p. 221-244.

NEGRO Sandra (2013) "Caracterización y clasificación de los esquemas de integración”. In NEGRO Sandra (dir.) Derecho a la Integración Regional. Manual. 2da. ed. Buenos Aires: Euroeditores/Ed BdeF; p 45-46. 